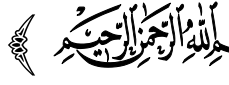

量

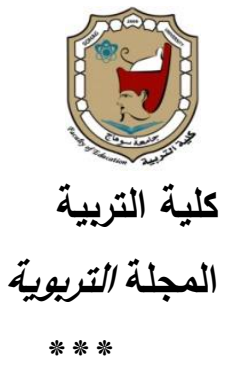

تعدد الروى الجمالية لامشفغولة الفنية الواحدة لإثراء مادة

\title{
الأشغال الفنهية
}

\section{list}

أ.م.د/ وجدى رفعت فريد

أستاذ الأثغال القنية المساعد

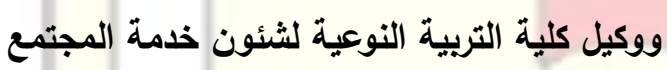

وتنمية البيئة - والمشرف على قسم التربية الفنية جامعة أسيوط

$$
\begin{aligned}
& \text { أ.م.د/ أميرة أحمد حسين } \\
& \text { أستاذ الأثغال الفنية المساعد } \\
& \text { بقسم التربية النوعية } \\
& \text { جامعة عين شمس لتربيه لنوعه }
\end{aligned}
$$
مدرس مادة بقسم التربية الفنية

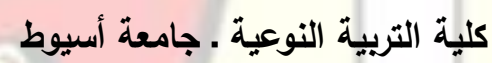
قسم التربية الفنية ـ تخصص (أثغال فنية) د/ منى مصطفى محمد عبدالرحيم 


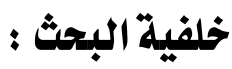

الدراسات الحديثه للفلسفات المعاصرة فى الفنون اتخذت منطلقا فنيا وتحريبيا متمشيا

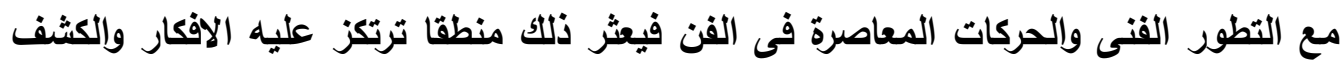

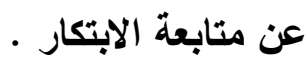

فكان التطور والتجريب من سمات العصر الحديث والمعاصر وما تبنته الاتجاهات الفنية الحديثة التى أعطت العمل أكثر من معنى وفكرة ورؤى متعددة من خلال ذلك يتحقى قيما

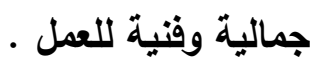

ويعتبر الفن الحركى kinetic Art من الفنون التى عبرت عن العمر الحالى والثوره

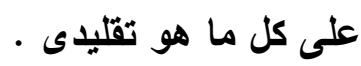
وقد أراد الفنان أن يعبر عن الحركة فى اعماله مؤمنا بان " الحركة فى المجال البصرى

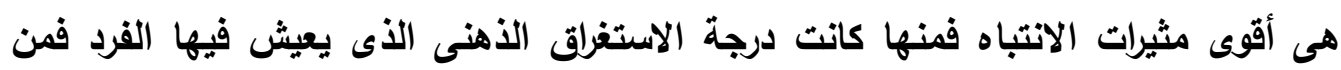

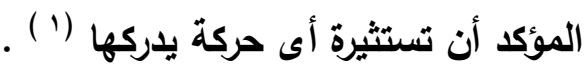

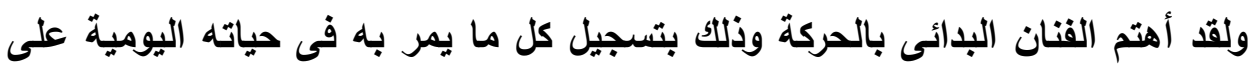

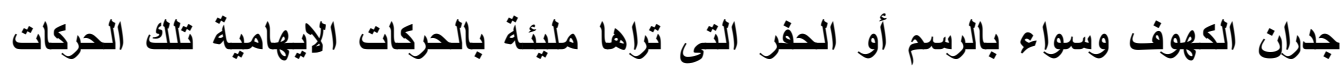

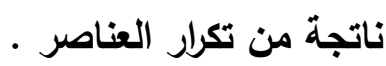

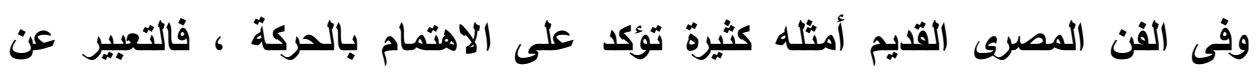

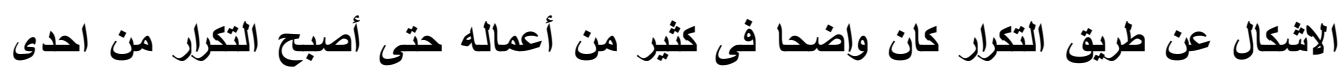

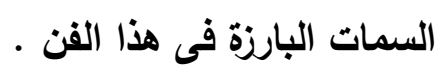
تكون للحركة دور فعال فى العمل الفنى عن طريق قوة سواء كانت تلك القوة طبيعية

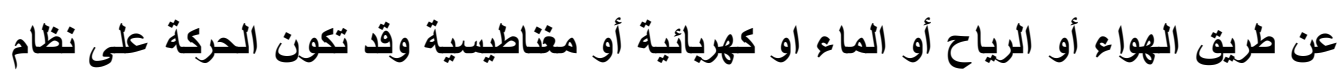
واحد أو متقطعة أو تتظللها بعض فترات السكون عن طريق للحركة التى قام بها كل من " فنانى الحركة" نجد أن العمل الفنى يشغل مكانا عن طريق الفئ انثائه في الفراغ ويالحركة أصبح

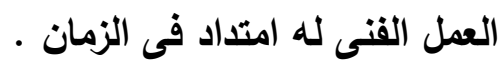

$$
\begin{aligned}
& \text { (1) عبدالفتاح رياض ع 19 1 ـ النكوين فى الفنون النتكيلية _ دار النهضة العربية . } \\
& \text { - YOS - }
\end{aligned}
$$


فالفنان يسعى دائما من خلال فنه للتبير عن الحركة والتى أصبحت الان حركة فعلية بعد أن كاتت إيهاميه وهذا هو الحال أيضا بالنسبة لمادة الاشغال الفنية فقد كانت البداية وهى فترة لها أهميتها ثم مرت أبحاث الاشغال الفنية بمرحلة هامة وهى محاولة النهوض بهان الهال لتكون على قدم المساواة مع الاتجاهات . وإلفلفات الحديث فظهرت أبحاثا تعتمد دراساتها على مدارس الفن الحديث وعلى أثر ذلك يجد الدارس أهمية عنصر الحركة فى العمل الفنى كمحاولة للأستفاده من هذه الخاصية ـ الحركة الفعلية حيث تتجه نحو دراستها وإدخالها فى مجال الاشغال الفنية للتحديث ومسايرة الاتجاهات الحديث والعصرية والبعد عن التقليدى فى الفن .

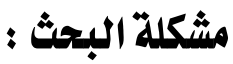
مما سبق وجدت الباحثة أن الفن الحركى كأمر الاتجاهات يتضمن جانبا فكريا وفلسفيا يتماشى مع مناهج ومقررات المادة الدارسية ـ ويمكن الاستفادة منه فى تحقيق الحركة الفعلية والتغيير فى شكل المشغولة الفنية ـ وخروجها من الثبات اللائم لها الى عملية التجديد والتغيير لوحدات العمل الفنى الواحد ليظهر لنا من نفس تلك العمل مجموعة من الوحدات

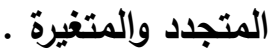
وعلى ذلك تتلذص مشكلة البحث فى التساؤلات الاتى :

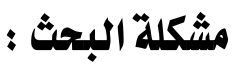
ما مدى الاستفادة من تعدد الرؤى للمشغولة الفنية الواحدة جماليا .

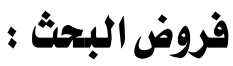
هناك علاقة إيجابية بين تعدد الروئى الجمالية المشغولة الفنية الواحدة وإثراء الأثغال

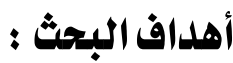
ا. يهذف البحث إلى أثراء المشغولة الفنية جماليا من خلال تعدد الرؤى للمشغولة

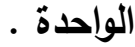




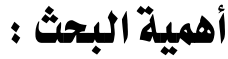

I. إثراء مناهج مادة الأثثغال الفنية وطرق تدريسها بمفهوم يواكب حركة الفنون المعاصرة . r. اكتثاف الوسائل التكنولوجية الحديثة التى تساعد على تحقيق الحركة فى المشغولة الفنية.

r. تزوير الطلاب بخبرات ثُقافية وفنية تفيد في إثراء مجال الأثشغال الفنية . ع. إيجاد حلول تثكيلية مبتكرة فى المشغولة الفنية .

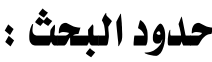
زمانية : القرن العشرون والواحد وعشرون ·

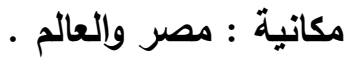

الحركة فى الفنون الحديثة فى الشفولة الفنية : مع بداية القرن العشرين تطورت شتى المجالات تطوراً ملحوظاً وسادت حالة من القلق والتغير وكادت تختفى القيم المطلقة والمقاييس التقليدية ، فحدثت طفرة كان لها تأثيرها الواضح على معظم المجالات ، فأصبح سمة هذا القرن هو القلق والتغير المستمر بل وعدم القدام الثبات وكان لمجال الفن فى هذا القرن نصيباً واضحاً من هذا التغير والتطور ، فلقد أصبحت

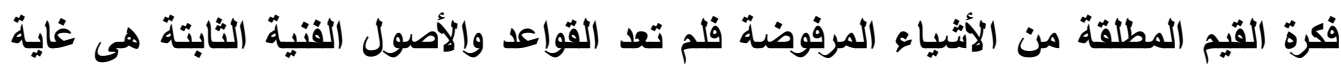

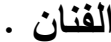

ويسعى الإنسان إلى التحديث لما ينطوى عليه من تقدم وتطور يتيحان فرصة تحقيق مستوى أعلى من الحياة ، ويتضمن التقلم والتطور إلى جانب ذلك الارتفاع بمستوى العلم

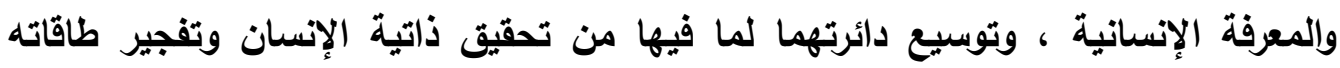

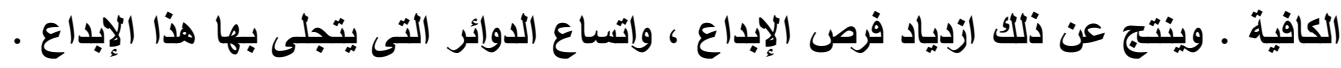

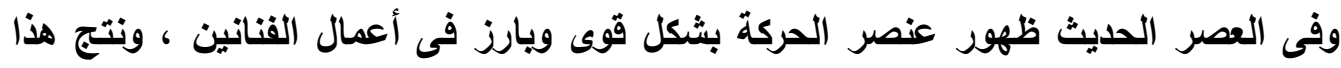
نظراً لظهور تطورات العصر ، حيث الاكتثافات العلمية والتكنولوجية التى تركت أثر كبير فى في الثئ

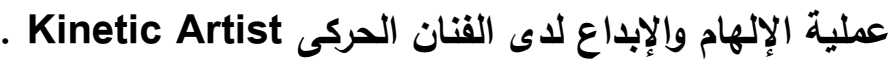
وقد ازدهرت الروح العلمية عندما يستخدم الفنانون فى العصر الحديث الحركة الفئة الميكانيكية أو البصرية ، أو الطبيعية مثلما استخدم " موهلى ناجى " الضوء استخداماً مباشراً 
فى الفن لإعطاء تأثير الحركة الواقعية ، وكان ذلك يقوم على أساس فهم علمى باللوحات

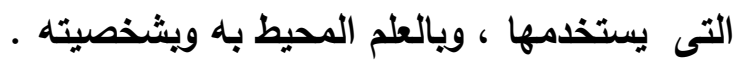
" والقنان يقوم فى مجال الفن الحركى Art بإجراء تجارب علمية وبتهية ، ويحتاج بالإضافة إلى معلوماته النظرية ، مساعدة العلماء فى استخدام أحدث الطرق التى تصلح لبناء أعمالهم الفنية وكان الفنان فى المذهب الحركى يسعى إلى تعميق العلاقة بين العمل الفنى والمشاهد فتصبح علاقة اتصال مباشرة ومتواصلة " ( (1) . ولقد تعدى الفنان مراحل التقليد والتسجيل إلى مراحل التجريب من خلال النظريات العلمية الحديثة ، حتى أنه انشغل بما هو أخطر من ذلك فلقد رغب فهى تحقيق عنصر الزمن هرجن فى أعماله وكان هذا درب من دروب الخيال آنذاكى ، إلا أنه تعدى ذلك بواسطة التعبير عن الحركة فى أعماله بشكل يوحى بحركة قد تكون إيهامية أو فعلية إلا أنها تضيف بعداً جديداً للعمل القنى ، وكثرت وتنوعت مظاهر الروئية الحديثة بين الاتجاهات والمذاهب المختلفة

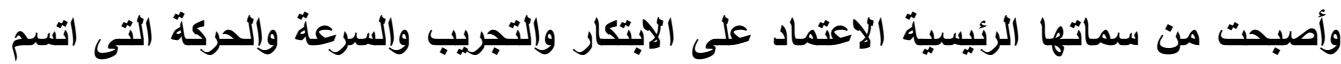
بهما هذا العصر أى انفعال للفنان ضرورة فى إعادة صياغة العناصر بشكل مختلف تحمل قيم تعبيرية وهذا سوف يكون نقطة البحث الحالى فى تغير شكل المشغولة الفنية من الثبات إلى

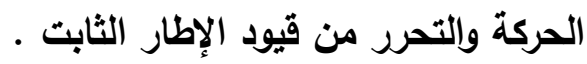

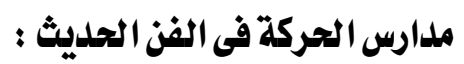
حاول الفنانون التعبير فى الفن التشكيلى بأفكار وأدوات مختلفة غير المعتاد عليها من قبل فيما يشبه انقلاب على جميع المعايير التقليدية . ولهذا ظهرت محاولات تحقيق عنصر الزمن بالنسبة للفن التشكيلى بالتعبير عن الحركة فقد بدأ التفكير فيه منذ العصور القديمة كما ذكرنا من قبل إلا أن الفنانين المعاصرين لم لم يكتفوا بذلك فأرادوا أن يحققوا الحركة ذاتها معتمدين فى ذلك على ما حلث من تقدم فى كافة

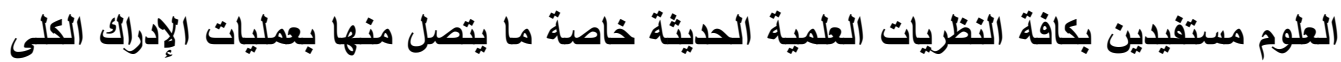

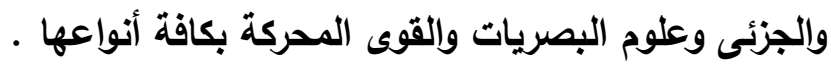


ويمكن اعتبار البداية الحقيقة للفن للحديث حيث نظر الفنان إلى العلم على أنه وسيلة لتغيير العالم ، وليس لمعرفته فقط ، حيث كان ما يميز العصر الحديث التطور الهائل للعلم وتطبيقاته الزائدة فى حياة الإنسان فقد كان على الفنان أن يتعايش ويتكيف مع عصر حاصرته فيه الآلة فى كل مكان لذلك فقد اهتم كثير من الفنانين بتصوير الحركة وإلسرعة فى لئ - أعمالرهم

وتكونت مجموعة من الأفكار الجديدة تعتمد على التقدم التكنولوجى واتجاهات حديثة مثل الحركة كعنصر أساسى فى العمل الفنى وسيحاول الباحث أن يتعرض للمدارس الفنية الحديثة التى تتسم بفنون التكنولوجيا الذين أثروا الاتجاهات الفنية وخاصة الفن الحركى بما

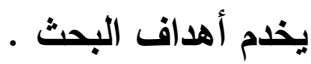
ومن خلال فنانى تلك المدارس يتحقق فعل الحركة فى المشفولة الفنية على سبيل

: Marcel Duchamp مارسيل دوشامبر وقد أبدع دوشامب فى احدى لوحاته التى عبرت عن الحركة عارية تنزل الدرج صورة (r • (r) فقد أوجد الزمن من خلال تسلسل الحركة لهذه المرأة وهى تنزل من السلم ، ومن خلال المدخل التحليلى والعرض التجريدى لعناصر العمل الفنى ، وهذا المفهوم الفلسفى التصورى يعتبر أهم دعائم المذهب المستقبلى ( ().

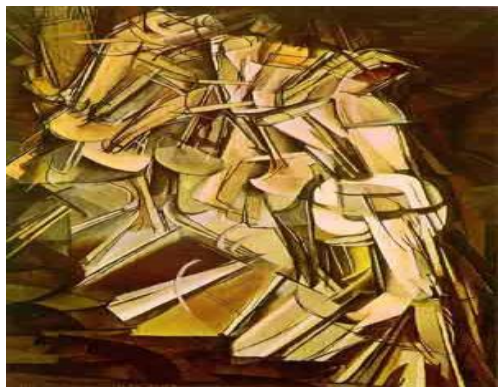

صورة رقم (1)

" مارسيل دوشامب " عارية تنزل الارجة - ب 19 19 19

H.H. Arnason 1977 History of modern Art, : نقلا عن

Thomas\& Hedson, London, P.577

(1) Herbert Read ; 1974, Aconcise History of Modern Painting , London, 1974, P:108. 
r. الفناز ( الكسندر رودتشينكو ) :

من أشهر فنانى البنائية وكانت أعمال الكسندر تتسم بالخطوط المستقيمة الحادة التى

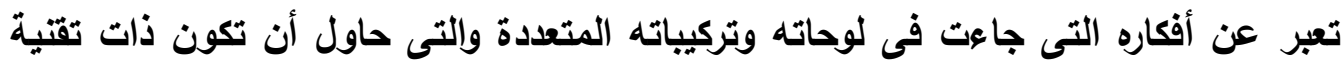

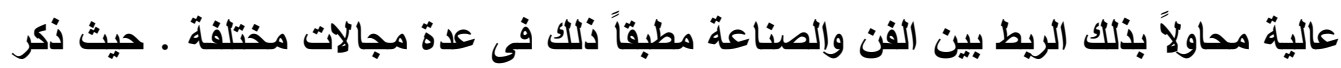

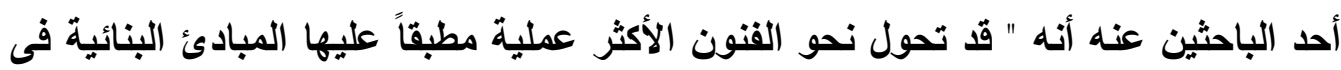
كل من صناعة الأثاث والديكور المسرحى والإعلانات والتصوير الفوتوغرافى" ( (') ومن أهم

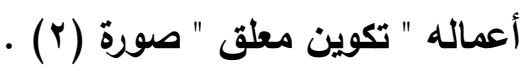

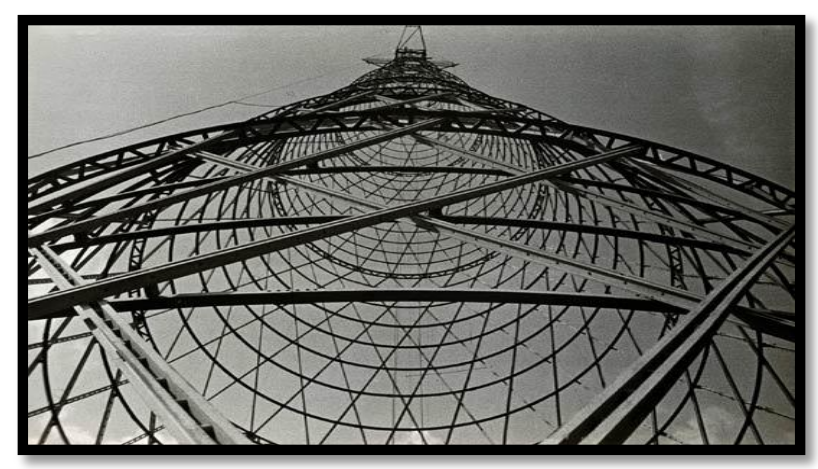

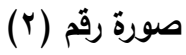

" الكسندر روشكو " تكوين معلق · ب ا9 ام نقلا عن

Peter Seliz : 1982 Art in our Times thomas \& Hedson, new York P. 280 . والفنان عصمت داوستاشى له عمل بعنوان (كرسى المدينة) صوره رقم (r) يمثل العمل

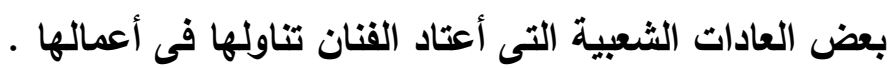

محسن محمد إبراهيم : بVr 19 ا : البنائية فى التصوير المعاصر والإفادة منها فى تدريس الفنون رسالة ماجستير غير 


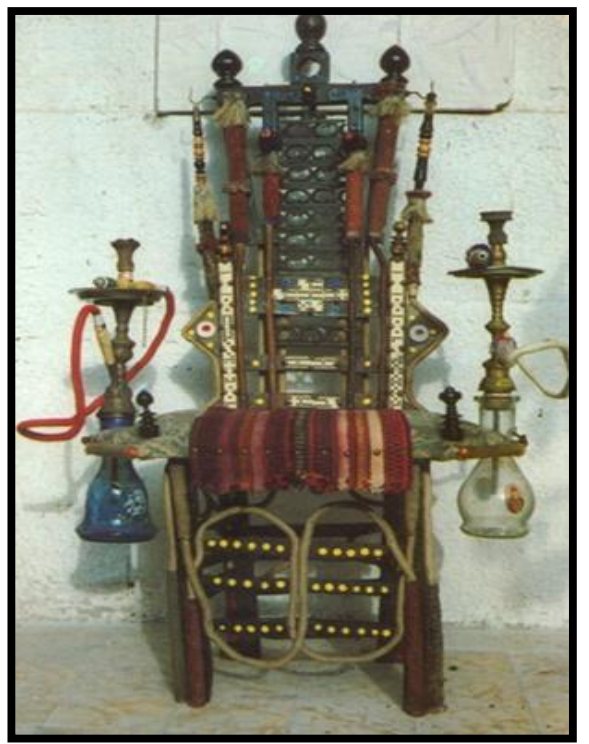

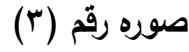

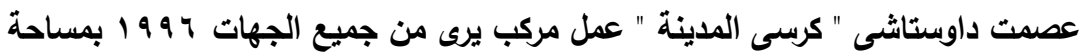

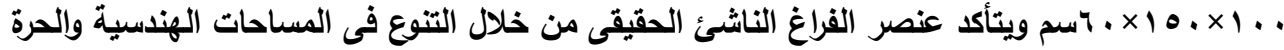

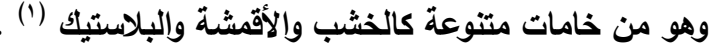

\section{مفهوم التفيير والتعلد فى علاقتات العمل الفنى :}

إن مفهوم التغيير والتعدد فى علاقات العمل الفنى. قـ جعل العمل الفنى الواحد متعدد

الصور والهيئات ، ولا يقتصر شكله وتركيبه على شكل واحد منذ إنتاجه وحتى يعنى .

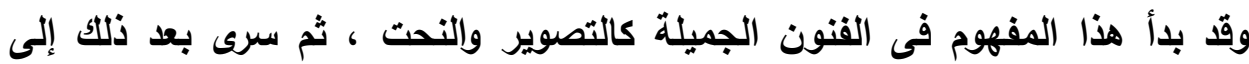

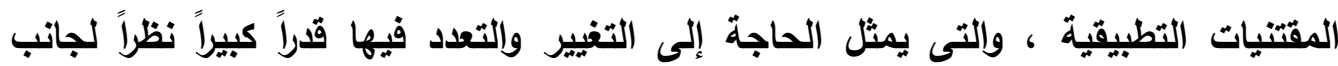
الاستعمال الوظيفى ، لذا فقد أصبح سمة مميزة للمشغولات القنية فى العصر الحديث .

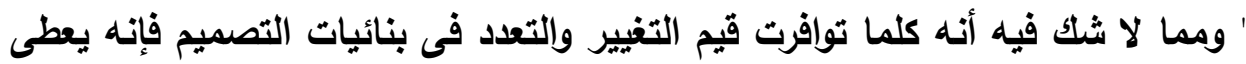
ثراء للمشغولة فى توافر تصميمات متعددة وثابتة لها باستخدام نفس عدد أجزائها ومفرداتها ويحركة يدوية بسيطة يمكن الحصول على احتمالات شكلية ولونية عديد ، فإن ذلك يزيد من القيمة الجمالية للمشغولة والوظيفية بما يساير روح العصر الحديث وقد ساعد كل من مفهوم التجريب ومفهوم الحركة التقديرية والفعلية على تطوير العمل الفنى من حيث الثكل ومن 
حيث المضمون لتعدد إمكاناته التثكيلية ليصبح أكثر إثارة ومتعة للمشاهد وكذلك أكثر إقادة

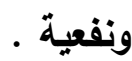

ومع تحقيق الحركة الفعلية البسيطة - التلقائية - وما أضافته للمشغولة من صياغات شكلية وقيم جمالية جديدة ، كان البحث وراء تحقيق الحركة التى يمكن التحكم فيها من جهة ويمكن تثبيتها بما يغير شكل العمل القنى بأكثر من مظهر جمالى من ناحية أخرى " ( ) .

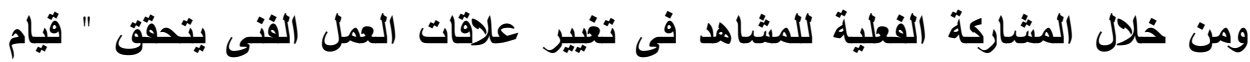
المشاهد بدور ايجابى تجريبى لممارسة وإدراك سلسلة من العمليات التحليلية للعلاقات التثكيلية فى العمل الفنى ، وإثارة روح الخلق والإبداع بدلاً من دوره القديم الذى لا يتعدى بلى

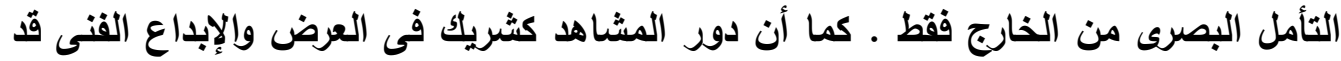
أوجد علاقة جديدة بين المشاهد والعمل الفنى ، فهذه الأعمال تتطلب من المشاهد أن يشترك فى الخلق والأداء الفنى ، كما يفعل الجمهور حين يشترك فى غناء المجموعة " (؟) . وقد تطور مفهوم التغيير والتعدد فى علاقات العمل الفنى والتى تعتمد أساساً على توافر الحركة الفعلية بين أجزائها من حركة تلقائية بسيطة ولحظية وغير متحكم فيها إلى تحريك أجزاء العمل أمام المشاهد بأساليب آلية مختلفة تغير من تركيب العمل وهيئته مثل إضافة مروحة علوية وموجهة ناحية أجزاء العمل ، ثم إلى تحريك متعمد من قبل المشاهد لتغيير

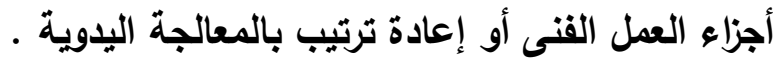
وفيما يلى التحليل الذى يتضمن أثر مفهوم التغيير فى المشغولة الفنية على بعض بله بله الجوانب التشكيلية فيها وهى :

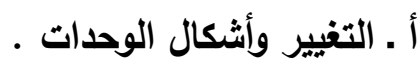
ب ـ التغيير والعلاقات اللونية .

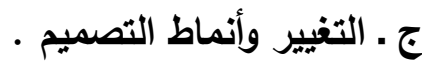
د. ـ التغيير والعلاقات التركيبية . .

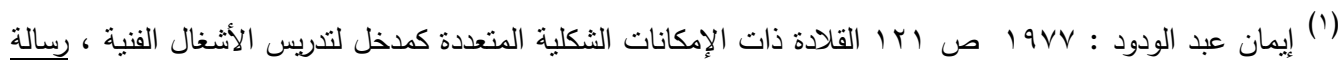

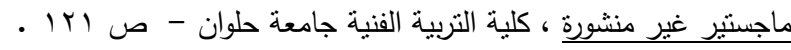
محمود عبدالعاطى : رسالة ماجستير - كلية التربية الفنية - جامعة حلوان - ص سب ا ، اس ا. 


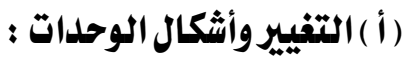

ينبغى توافر عدة مواصفات لهذه النوعية من المشغولات المتحركة منها. توافر علافتى التكامل يبين الأجزاء الداخلية الغير ظاهرة من العمل والأجزاء الخارجية التى تحتوى على عمل فنى أخر ، بحث لا يؤثر فى بعض الأعمال على الإخلال من اتتلان العمل أو عدم التوافق بين أجزاء المشغولة سواء الداخلية أو الخارجية بحيث ينتج عمل فئى الأنى

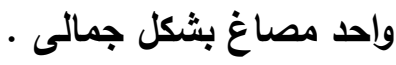

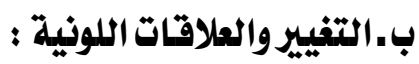

" ولكى تتوافر قيمة التغيير والتعدد فى العلاقات اللونية فإنه من الأفضل أن يوضع

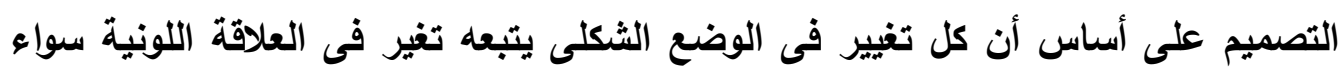
عن طريق التغيير فى كنه أو درجة اللون ذو المساحة ذات الوضع الجديد بالنسبة لكنه الألوان المجاورة فتصبح علاقة تضاد لونى أو علاقة توافق متعددة الدرجات " (1)

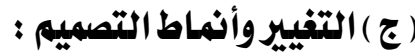
لاثثك أن التغيير وتعدد العلاقات الثكلية بين عناصر تصميم المشغولة كان هدفاً

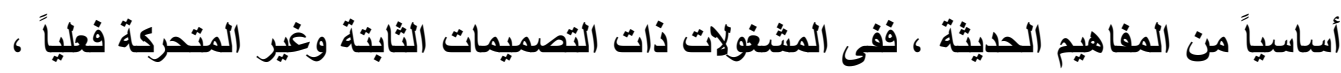

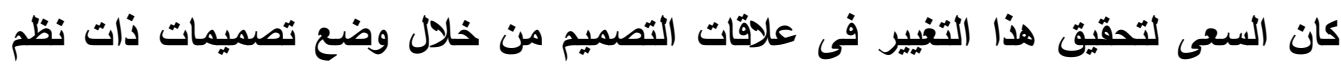
إيقاعية منضبطة بين الأثكال والفراغات أو الأثكال والأرضيات تكون ذات التهئ مسئوليات متعددة

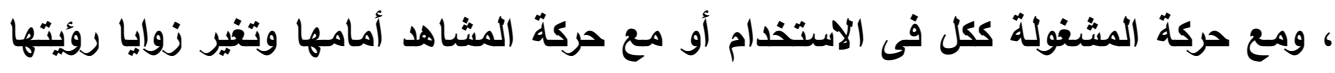

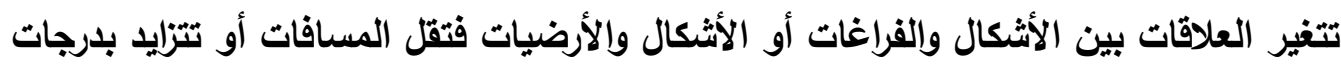

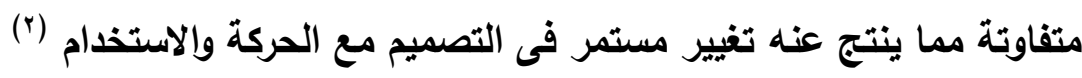

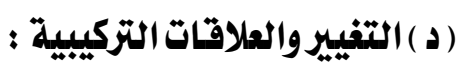
إن التغير الفعلى بين اجزاء المشغولة لإنتاج علاقات جديدة ينتج عنه بالضرورة تغيير

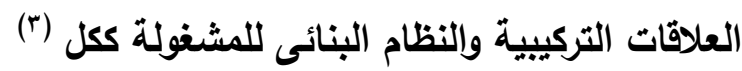

(1) Lee Nomess :, 1970 objects : usa, Astudio Book, The Viking press, New York: P 203.

(1) jahn Toveg : 1971 The technique of Kinetic Art, B-T- Batslord, .p-50.

${ }^{(2)}$ Brandara lee Diamonstein : Handonadein America . op - cit p.23 . 
وتقسم اتجاه الحركة فى المشغولة الفنية إلى قسمين :

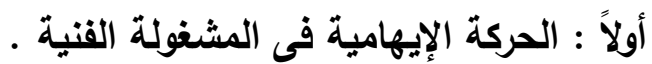

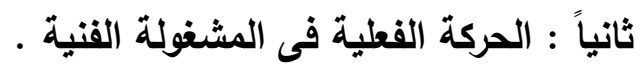

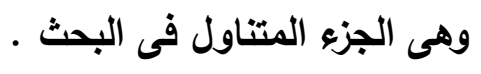

ثانياً : الحركة الفملية فى المشفولة الفنية :

عرفت الحركة الفعلية باسم " الفن الحركى Kinetic Art " ، ونثأت من خلال الأشكال المجسمة ، وعلاقتها بعنصر الفراغ الحقيقى الموظف من خلال عناصر المشغولات ولتحقيق جانب الحركة الفعلية فى المشغولة القنية لابد أن تخضع المشغولة لكثير من الضوابط نظراً لارتباطها بالجانب الجمالى والوظيفى وكذلك ملائمة عناصر تصميمها ووحداتها

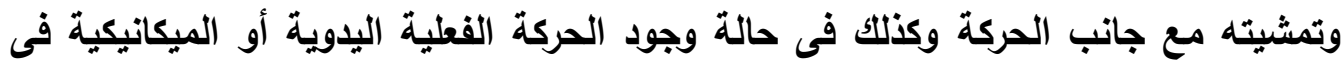
المشغولة فإنه يجب أن يكون هناك حسابات رياضية خاصة لعنصر الفراغ الحقيقى الناشئ

من الأشكال المجسمة (1)

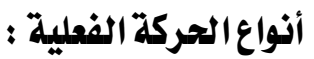

والحركة الفعلية فى المشغولات تتعدد أيضاً أنواع الحركة الفعلية Kinrtic بشمول ووضوح لتوسع من مدركات الأعمال الفنية ومفاهيمها " فالقن الحركى هو بمثابة تعبير عن امتداد العمل القنى فى الزمان مثلما امتد فى المكان ، أما الحركة فهى القدرة على التنفس بحرية فى أبعاد جديدة ، وهى اللغة التى يمكن التعبير بها عن إدراك الفنان لحقيقة الفراغ، كما أن الأبعاد التى يكسبها الفنان لعمله أو يوصلها من خلاله هي ذاتها ذها أبعاده الباطنة فيه"

وهناك الحركة الفعلية اليدوية التى تتم بواسطة اليد ، وأيضا الحركة الفعلية المركبة التى تدور من خلال الأجهزة والموتورات وأيضا الحركة التى تعتمد على الهواء والرياح

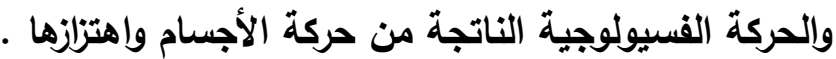

(3)Myron I.braunstein(1976) : Depth perception through motion, publishers Asubsieliary of har court Brace Jodvnovich, New york, Sanfran cisco, p.(77)

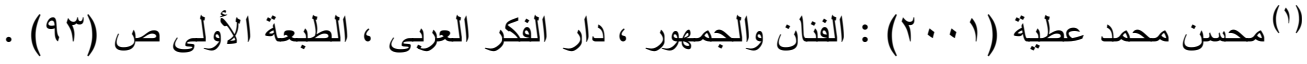




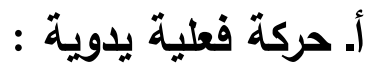

هناك بعض الأعمال والمشغولات الفنية التى تصاغ من خلال عمليات التركيب على التى محاور رأسية أو أفقية أو مائلة وتتحرك بواسطة اليد بدوران تلك الأثثكال أو إزاحتها من فن وضعها التى عليه ، أو فكها وتركيب شكل آخر ليظهر مكان الثكل السابق ، فتتغير معالم

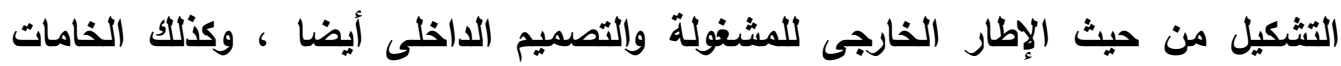

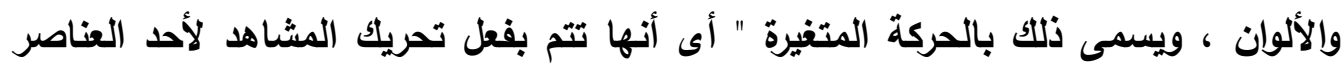
الاخلة بالعمل فينتج عن ذلك مشغولة فنية أخرى متغيرة بفعل المشاركة الفعلية للعمل الفنى. وهناك بعض الأعمال الفنية التى صيغت لأثكال الإنسان وإلحيوان والدمى ، ووظفت فيها الخامات المتنوعة مثل السلك وشرائح البلاستيك ومن تلك الأعمال مشغولة فنية صورة الأليكان (؛) وتبنى على الحركة اليدوية المحورية الرأسية وصيغت من خامات متنوعة مثل خامات البنات اللائن الصناعية الملونة ، والمعدن والخشب .

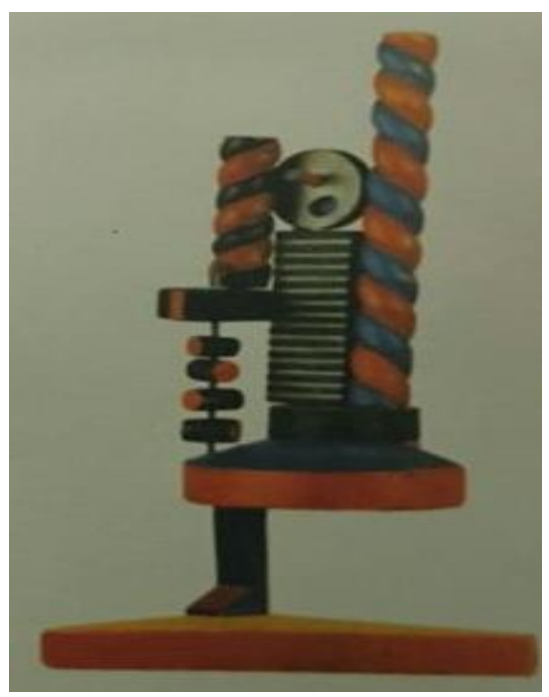

صورة (飞)

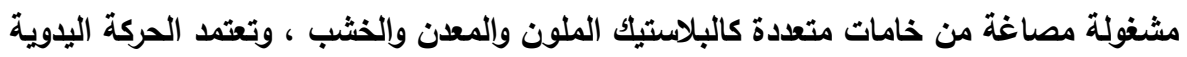

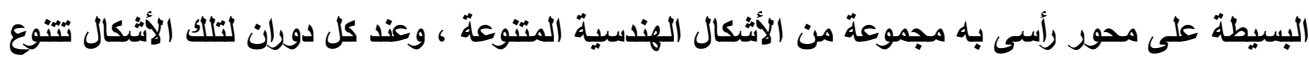

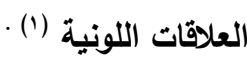

${ }^{(1)}$ Karl Ruhrbeng (2000) : art of the 20 century, taschen, Koln, london, P. (436). 
ب. بركة فلية بالقوة الكهربائية ؛

تتم الحركة الفعلية الميكانيكية عن طريق القوة الكهريائية (الموتور) كأعمال الفنان البلجيكى " بول بيرى Pol Bury " الذى صاغ أعمالا فنية اعتمدت على وجود محرك كهريائى غير مرئى بحيث يتحرك حركة بطيئة وكذلك نرى أعمال الفنان " ناعوم جابو" الحركية

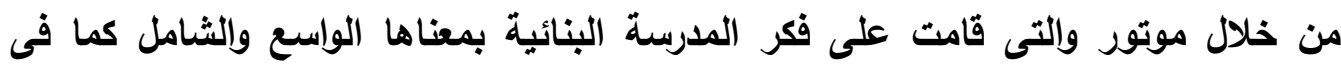

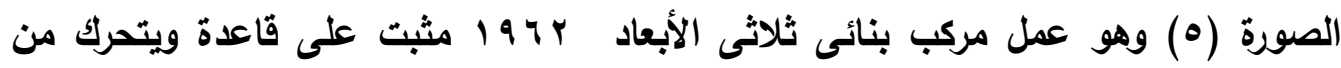

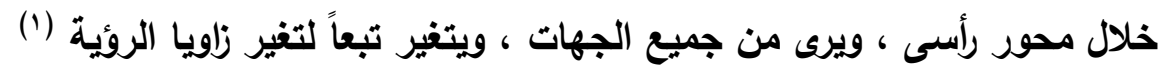

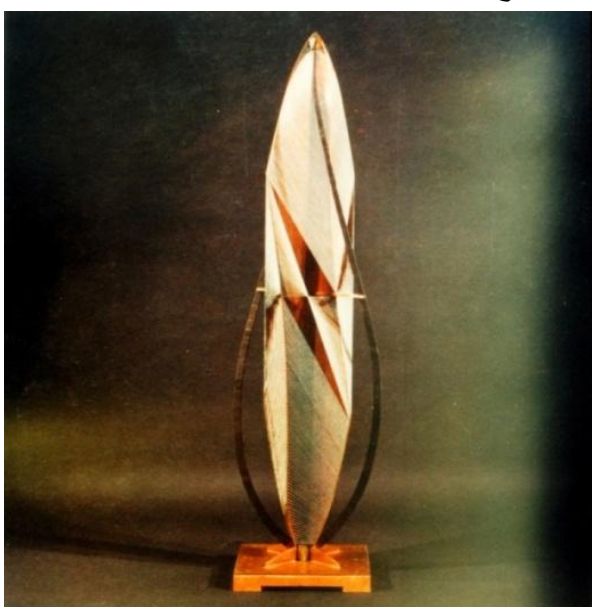

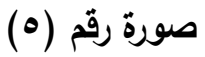

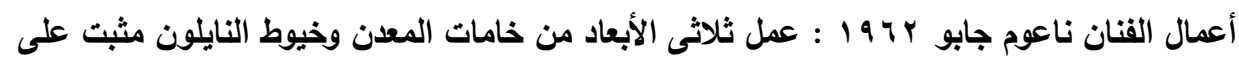
قاعدة ويتحرك من خلال محور رأسى " حركة ميكانيكية "

أعمال فناذين تناولوا الحركة في أعمالهم :

هناك الكثير من الفنانين الذين اهتموا بعنصر الحركة الفعلية منهم العالميين والمحليين وكان يقوم ذلك على أساس علمى سليم بالوسائل التى استخدموها ويالعلم المحيط بهم وذلك الكين

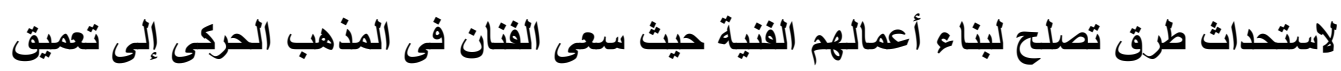

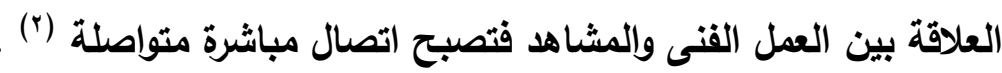

(1) Naum Gab (1987) : Sechzig Jahr Konstru ktivismus, prestel, velage Mvnshen . p. (91) .

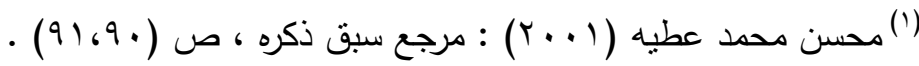

$$
\begin{aligned}
& \text { - rqo- }
\end{aligned}
$$


أعمال الفنان " كالار " المعلقة فى الهواء والتى بناها من خامة السلك كإطار خارجى لها ، أو خامات البلاستيك الشفاف بألوانه المختلفة ، وعلقها بواسطة خيوط النايلون صور

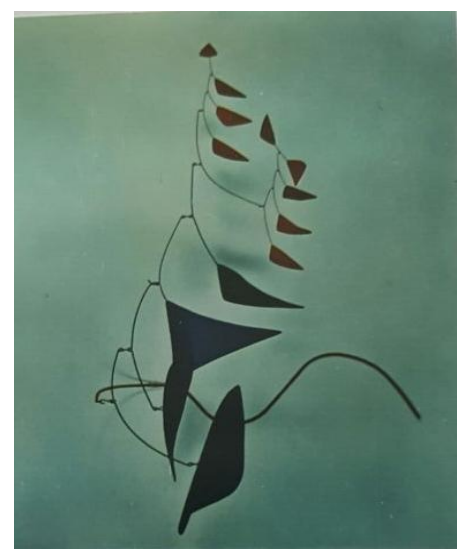

صوره (7)

الفنان كالدر 9 9 9 امشغولة مصاغة من البلاستيك الثفاف الملون وخيوط النايلون واعتمدت الحركة

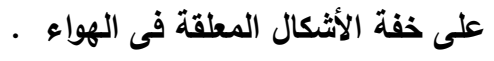

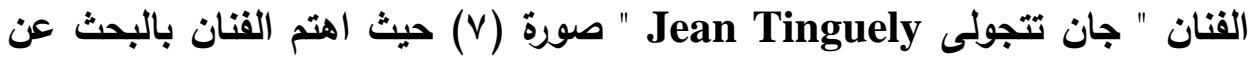
حيل جديدة للكشف عن الطاقة المجردة فى قلب أعماله حيث اتسمت تلك الأعمال بالحركة والضوضاء وعبرت عن نوع ما من الاضطراب وصيغت أعماله أيضاً من بقايا ونفايات

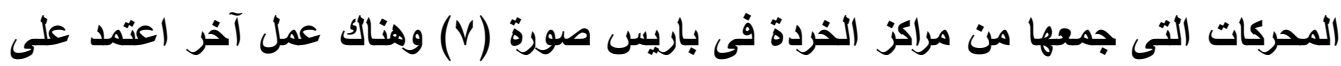
التحريك بالإزاحة ليحل شكل مكان اخر صورة (^) .

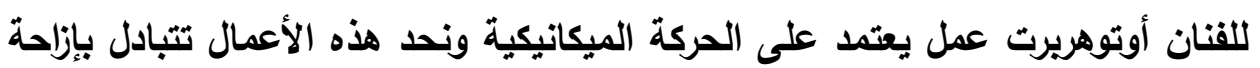

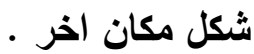

(') Giovanni Carandenente (1968) : calder mobiles and carandenente,the New American library, New York, p. $(5,6)$. 


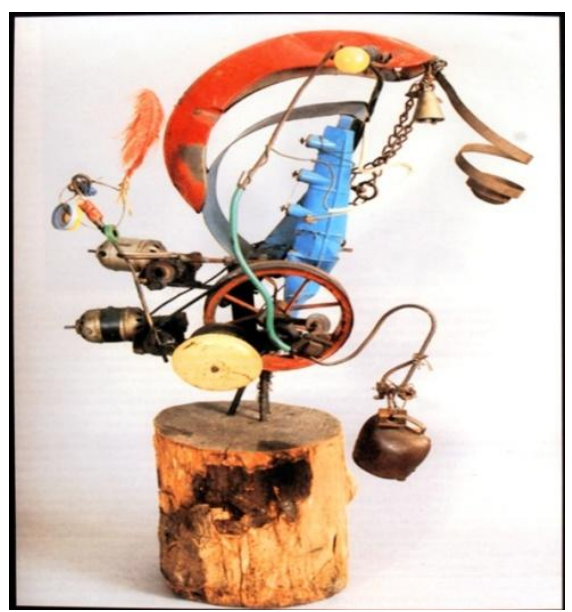

(V) صورة

"جان تتجولى " باليويا رقم ب لودفيبج من خامات متعددة مثل الخشب والمعدن وشرائح البلاستيك ( )

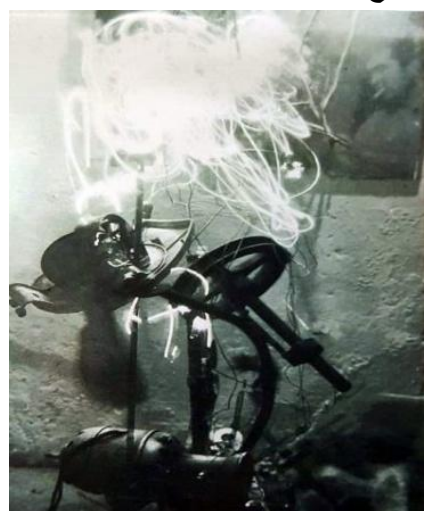

صورة (^)

" جان تتجولى "أثكال متحركة تعتمد على المؤثرات الضوئية من خامات متعددة مثل أنابيب البلاستيك

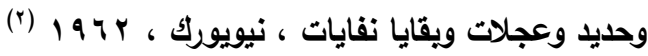

(1) Jonathon fine berg 1995 : Art since 1940 "Laurence King publishing. p. 229.

أحمد عبدالغنى محمد سالم : ( . . r) السبرانية كمدل لتحويل مفهوم التصوير إلى فن ما بعد الحداثة للقرن الحادى

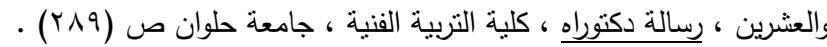

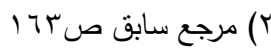


وهناك عمل فنى للفنانه سوزان هيفونا Susan Hefuna صوره رقم (9) وهو مزيج من مؤثرات الصوت والصوء التى اعتمجت عليها الفنانه لإحداث تركيبا دراميا لوحدة العرض هي تعطلى الإحساس بالغموض • والعمل مصاغ من خامات متعدده كالبلاستيك والمعدن(r)

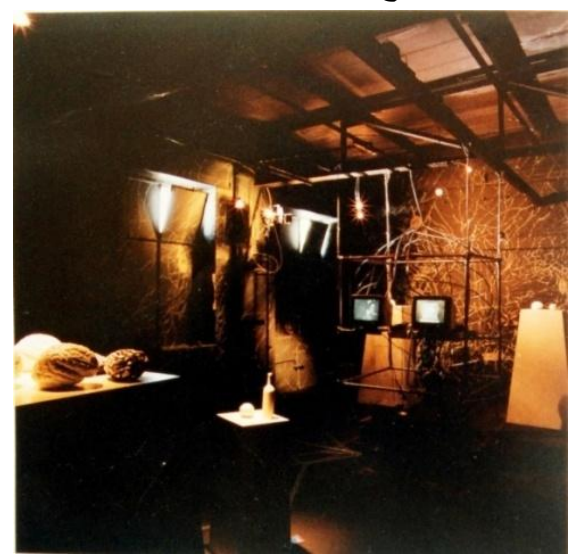

صورة (9) (9)

"سوزان هيفونا " عمل مركب فى حيز الغرفة مجمع الفنون ، الزمالك ، ب9 99

رابعاً : خصائص المشفولة الفنية القائمة على الحركة الفملية المتفيرة :

اعتمدت المشغولة القنية القائمة على الحركة الفعلية على عدة خصائص تميزت بها

عن غيرها من سائر الأعمال الفنية نستطيع أن نصيغها من خلال عدة عناصر محددة :

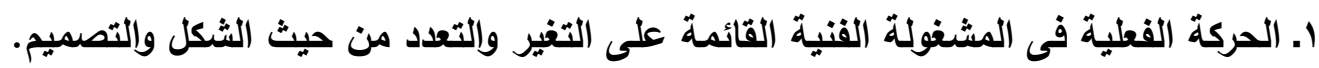

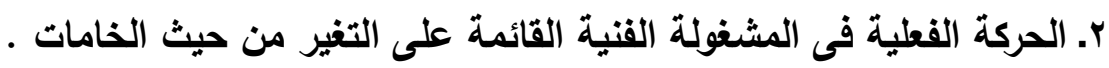
r. الحركة الفعلية فى المشغولة الفنية القائمة على التغيير من حيث العلاقات التركيبية.

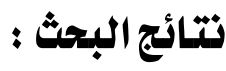
اـ أن التقدم العلمى والتكنولوجى أثرا إيجابيا على المشغولة الفنية . r. الحركة بأنواعها تعطى صياغات مختلفة للمشغولة الفنية لتكسبها رؤى جديدة .

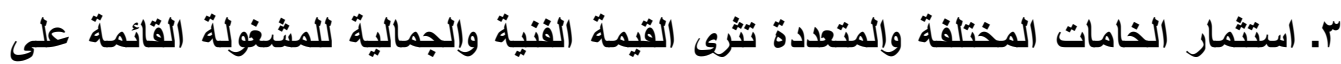
التغيير والتعدد فى الروئية كما تثرى مجال الأشغال الفنية بوجه خاص . ع. يمكن استخلاص بعض الرؤى القنية عن طريق الحركة والتى ينتج عنها التغيير فتتسم بالبساطة وسهولة التنفيذ لاستخدامها فى المجال التعليمى فى مادة الأثخال القنية . 


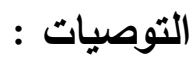

ا. توصى الباحثة بالاهتمام بالمشغولة الفنية القائمة على التغيير والتعدد فى الروئية التشكيلية لها لإثراء القيم الفنية والجمالية للمشغولة فى مادة الشغال الفنية . r. تحفيز وتثجيع ممارس الفن على الاهتمام بالتجريب لمواكبة التطور التكنولوجى ومعطيات العصر - مهم r. تدعيم ورش الأشغال الفنية بأقسام التربية القنية وتزويدها بالتجهيزات والمعدات والأدوات

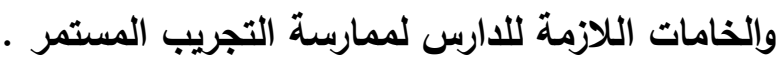
ع. توصى الباحثة بضرورة الاهتمام بمتطلبات العصر الحالى فى تنفيذ مشغولات فنية معاصرة تتسم بالحداثة وذلك عن طريق استثمار معطيات العصر الحديث من خامات وأدوات وتقتيات جديدة . 


\section{المراجع}

(1 ) عبدالفتاح رياض ع 19V _ التكوين فى الفنون التثكيلية _ دار النهضة العربية .

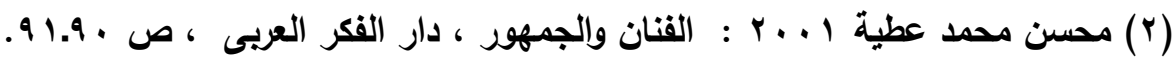

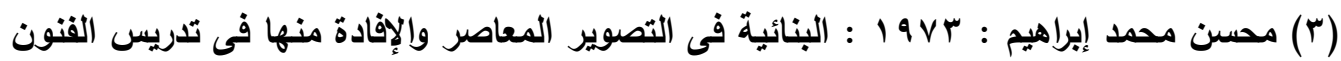

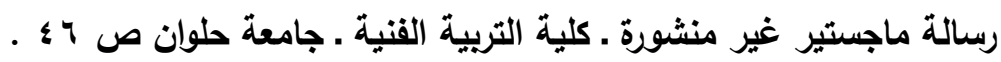

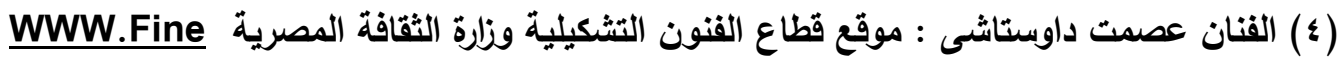
. art. Gor.eg

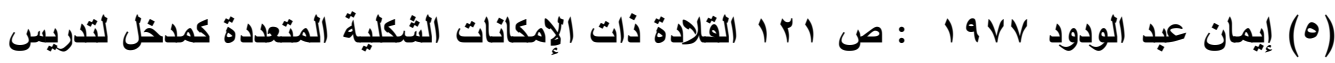

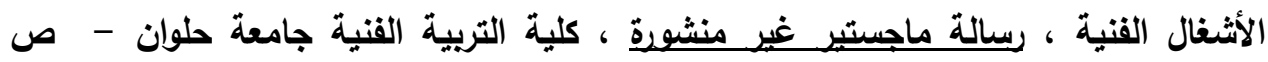

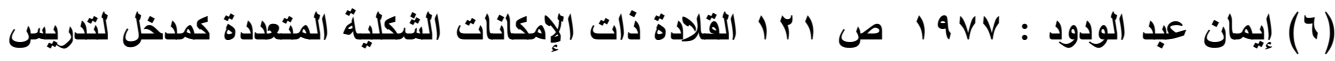

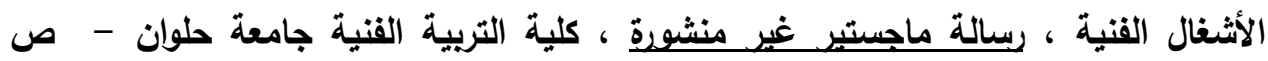

محمود عبدالعاطى : رسالة ماجستير - كلية التربية الفنية - جامعة حلوان - ص س Y V) $.1 \%$

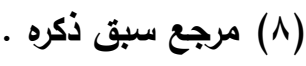

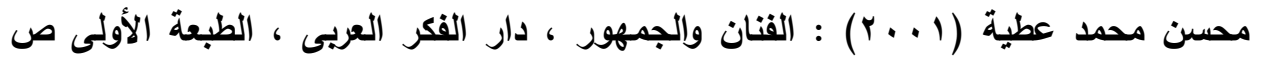

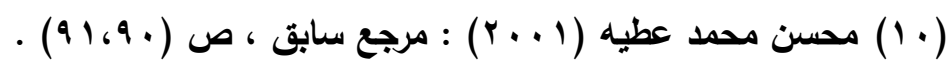

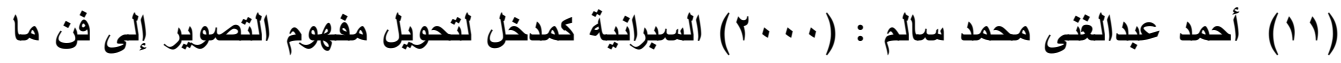

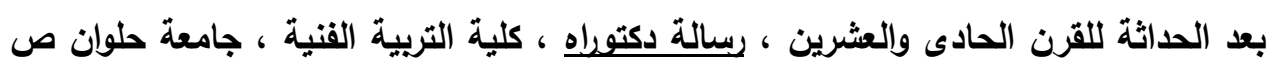

\section{المراجع الأجنبية :}

(1) Herbert Read ; 1974, Aconcise History of Modern Painting, London, 1974, P:108.

(2) Lee Nomess :, 1970 objects : usa, Astudio Book, The Viking press, New York: $P 203$.

(3) jahn Toveg : 1971 The technique of Kinetic Art, B-T- Batslord, .p-50.

(4) Brandara lee Diamonstein : Handonadein America - op - cit p.23 . 
(5) Myron l.braunstein(1976) : Depth perception through motion, publishers Asubsieliary of har court Brace Jodvnovich, New york, Sanfran cisco, p.(77)

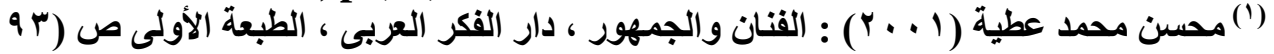

(6) Karl Ruhrbeng (2000) : art of the 20 century, taschen, Koln, london, P. (436).

(7) Naum Gab (1987) : Sechzig Jahr Konstru ktivismus, prestel, velage Mvnshen • p. (91) .

(8) Giovanni Carandenente (1968) : calder mobiles and carandenente,the New American library, New York, p. $(5,6)$.

(9) Jonathon fine berg 1995 : Art since 1940 "Laurence King publishing. p. 229. 